\title{
Motivational Orientation and Language Acculturation Experienced by English Speaking Adults Learning Arabic in Saudi Arabia
}

\author{
Safaa M. Abdelhalim \\ College of Languages and Translation, Al-Imam Mohammed Ibn Saud Islamic University, KSA \\ Mss. Hajar Abdulrahman Alqubayshi \\ Arabic Language Teaching Institute, Al-Imam Mohammed Ibn Saud Islamic University, KSA
}

\begin{abstract}
This study aimed to explore in-depth the process of second language acquisition in a broader context than classrooms and gain a greater understanding of language acculturation process abroad. It mainly examined the influence of various factors on the language acculturation strategy adopted by L2 learners, including socio-demographic data, language proficiency level, motivational orientation for learning L2, and perceived language acculturative stress. The study targeted a sample of fifty English-speaking bilingual female adults learning Arabic as a second language in Saudi Arabia. Data were collected with the use of three scales: motivational orientation for learning Arabic as an L2, language acculturation within the hosting society, and language acculturative stress. Also, a semi-structured interview was used to gain a deep understanding of the language acculturation process as experienced by the research sample. Quantitative results proved that, first, participants' integrative orientation to learning Arabic was higher than instrumental motivation; second, participants were more adjusted to their native culture with the majority having a little of language acculturative stress. Regression analysis revealed that only age and nationality had a statistically significant effect on the language acculturation level. The results of the interview showed parallelism with some of the quantitative results of the study. Some pedagogical implications and future research issues are discussed.
\end{abstract}

Index Terms —second language acquisition, motivational orientation, acculturation, acculturative stress

\section{INTRODUCTION}

Second language acquisition (SLA) field, based on post- constructivism theories, has witnessed a massive interest in investigating the relationship between the learner and the target language as well as its context. Advocates of these theories believe that linguistic competence results mainly from practicing in different social and cultural situations rather than being just a step that precedes linguistic performance. On this view, Hall, Cheng and Carlson (2006) stated that SLA is not attained inside the human brain only; it mainly takes place through participation and communication in interactive situations using different cultural tools in a complex social and cultural context that needs study and analysis. In other words, social and cultural factors are considered crucial in second language teaching and learning, as language, culture, and community are inextricably connected and mutually linked (Alareik, 2016).

Moreover, SLA research findings have indicated that some second language (SL) learners turned out to be more advanced at acquiring the target language than others even though they are following identical processes and materials. As an interpretation for this phenomenon, Dörney (2005) and Olivares-Cuhat (2010) stressed the importance of investigating the influence of learners' characteristics as indicators of the ultimate success in SL learning; these characteristics are defined in four categories: cognitive factors; affective factors; meta-cognitive factors; and social/demographic factors. Affective and social factors are considered the key factors that determine success in the multi-faceted process of second language acquisition (Gardner 2006; Nosratinia, Abbasi \& Zaker, 2015).

In the context of learning a second language abroad, learners often are more sensitive to the feelings and experiences they perceive in the surrounding environment of the hosting culture. Thus, many relevant research studies in various contexts (Alamaj, 2019; Dewaele and Al-Saraj, 2015; Midraj, Midraj, O’Neill \& Sellami, 2015) stressed that learner's motivation and attitudes are key concepts in second language research.

On the other hand, L2 researchers have come to acknowledge increasingly the impact of the language learning environment (context) and cutbacks of psychologically-based approaches that rely mainly on individual learner's selfreport about their motivation (Temples, 2013). Although the effort and commitment L2 learners exert in learning the target language depend to some extent on their interest in the language itself or the process of language learning, the current study aims to manifest that the desire to learn an L2 is also well associated with social context and especially to the communities in which that language is valued. Ozer and Schwartz (2016) declared that due to increasing globalization and instant intercultural contact nowadays, acculturation has become a complicated and multifaceted issue that is imperative to address. 
Being a highly synthetic and multidimensional process, there is no single theory that can help in getting a comprehensive understanding of SLA. Thus, instead of full dependence on one approach, all approaches should be correlated in dealing with SLA to better understand this phenomenon, (Atkinson, 2011). One of the main driving forces behind L2 acquisition in the context of the hosting society could be attributed to the complex relationship between motivational orientation and adopted acculturation strategy.

Accordingly, understanding the correlation between motives, goals, and acculturation could be essential in the context of learning an L2 abroad, as this requires learners to interact in a different culture, live unfamiliar experiences and try to some extent to adapt to the hosting culture (Bluestone, 2015; Rubenfeld, Sinclair, \& Clément, 2007). Yet, up to the researchers' knowledge, no study has taken into account the motivational orientation, acculturation, and perceived acculturation stress associated with learning Arabic as one of the highly critical languages by English speakers living in the Saudi community.

Most research studies in the field of learning Arabic as a second language (ASL) abroad targeted either learners' motivation from psychological perspectives or social factors. Research has hardly addressed the complex social and cultural influences on their learning processes. Drawing on Schumann's $(1978,1986)$ acculturation model theory and Gardner's $(1985,2001)$ socio-educational model of second language acquisition as a theoretical lens and data on ASL learners studying in Saudi Arabia, this study seeks to investigate the interaction between social and affective factors on the part of second language learning (SLL). The primary purpose of this study was to explore language acculturation process experienced by multicultural English speakers learning Arabic in Saudi Arabia. It also examines the influence of various factors on the language acculturation strategy adopted by the participants; including socio-demographic data, language proficiency level, motivational orientation for learning Arabic, and perceived language acculturative stress.

A. Questions of the Study

To achieve this aim, the study revolved around answering the following questions:

1. What is the level and type of participants' motivational orientation (integrative - instrumental) towards learning ASL?

2. What kind of strategies can be adopted by ASL learners in the process of socialization and acculturation in Saudi society?

3. What is the level of language acculturative stress perceived by the participants?

4. In what ways do participants' socio-demographic data (cultural background, age, \& length of residence in the hosting society), Arabic language proficiency level, motivational orientation toward learning it, and perceived acculturative stress correlate to their language acculturation strategy in the hosting society?

\section{B. Significance of the Study}

The results of this study can contribute to the SLA research filed by highlighting the significance of developing cultural diversity, intercultural competence, and empathy within the context of SL instruction. Besides, aiming to enhance second language learning proficiency, the study provides essential information to L2 syllabus designers and educational administrators about vital cultural and psychological aspects of language learning to be included in materials, classrooms, and programs. The results of this study can also assist ASL as well as other L2 instructors all over the world in understanding what affective and social factors to foster to help learners better achieve language attainment and avoid any sense of ambiguity in the acquisition of the targeted language.

\section{LITERATURE REVIEW}

\section{A. Learning Arabic as a Second Language}

Arabic is described as a condemnatory language due to its importance at international political and economic levels. It has gained more popularity among foreign language learners, as it becomes one of the most extensively spoken languages all over the world over the last ten years (Jackson \& Malone, 2009). Described as a critical language that has geopolitical significance worldwide, Arabic language has an important instrumental value (Al-Batal, 2007).

One reason behind the increase in learning Arabic as a second language (ASL) in gulf area is the state of massive economic development that the area is witnessing, thus attracting expatriates from different foreign countries. Also, As Saudi Arabia is the center for all Muslims all over the world for learning about Islam, a dire need to learn Arabic Language among foreign Muslims has emerged. Depending on such an intriguing interest in studying Arabic, researchers have started to investigate the motivation behind this growth and its consistency (Allen, 2007)

\section{B. Difficulties of Studying Arabic as a Second Language}

Arabic as a synthetic rather than analytic language has features that distinguish it from English or other IndoEuropean languages. According to Ryding (2006), along with the range of Arabic spoken varieties in different countries diglossia, as a sociolinguistic feature, is at the top of the difficulties that face ASL learners; as in order to master the language, they have to study two distinct varieties of it: Modern Standard Arabic (MSA) is used for formal written communication, while Colloquial, or dialect forms, that differ from reign to another, are used for spoken communication. Between these two distinct varieties, there exists a variety of intermediary Arabic called Educated 
Spoken Arabic (ESA), resulted from the standard and colloquial blend and thus containing elements of both spoken and written Arabic.

Such dual use in Arabic language constitutes a problem to learners of ASL in having two varieties of the language and double sets of vocabulary items to learn. There is a firm opposition from many AFL researchers to using colloquial varieties in teaching Arabic to non-Arabs (Madkour and Haridi 2006). They argue that MSA must be the medium for teaching Arabic because it is the common variety all educated people across the Arab world use. On the other hand, Wilmsen (2006) argued that focusing solely on MSA in language classes causes students frustration as they do not have the chance to master communicative competence in a natural away.

Other difficulties facing ASL learners include the Arabic orthographic system (depending on a constant system, Abjad, instead of using alphabetic writing system), and the wide difference between English typology and Arabic language in terms of number of syntactic, morphological, and lexical features. Thus, ASL learners feel overwhelmed by the number of rules that they have to learn to speak Arabic. The impact of these difficulties on the process of acquiring Arabic as a second language has been identified and observed but still need to be studied in depth depending on either sociocultural or cognitive approach to second language learning (Temples, 2013).

\section{Acculturation and L2 Acquisition}

Based on the theory of second language acquisition (Schumann, 1978, 1986) and socio-psychological adaptation in cultural diversity, acculturation pattern has been postulated to function as a predictor of success in second language acquisition (Mohamed \& Othman, 2015; Waniek-Klimczak, 2011). However, one perspective sees that SL acquisition itself as a component of the acculturation process. This simply means the more positively oriented and psychologically integrated into the target language community, the more successful SL learner be in the process of acquiring the target language (Mei, Raymond, Tracy \& William, 2009).

The acculturation process is highly variable following moderating factors relating to both groups and individuals. Personal factors such as age, gender, education, and socioeconomic status are said to affect the acculturative adaptation. Moderating factors relating to the group include cultural distance, social support, prejudices, and the reason for intercultural contact. Time is also regarded as an important factor, as the temporal progression of the acculturation experience indicates different phases of stress and adaptation. It has been stressed that all these factors should be included in a proper acculturation psychological study; however, no study has incorporated all the aspects of the framework, indicating room for advancement (Berry, 1997).

Reviewing related literature, it became clear that there are three main leading models for investigating the effects of social context on SLA: Schumann's Acculturation Model (1978, 1986), Giles's and his associates Inter-Group Model (Beebe \& Giles 1984; Giles \& Byrne 1982), and Gardner's Socio-Educational Model (Gardner, Lalonde \& Pierson, 1983). Each of these models has some specific points of strength and weakness (Graham \& Brown, 1996, p. 238).

Bluestone (2015) declared that the main difference between Schumann's acculturation model and Berry's model is that Schumann's model postulates that social contact between L2 learners and target culture members is basic, whereas Berry's model allows for the probability of limited or no contact between groups. Rudmint (2009), who is a prominent acculturation researcher, highlighted that depending on multi-dimensional scales for measuring acculturation is misleading and leads to confusing results. Based on this premise the present study adopted Schumann's acculturation model (host cultural involvement (integration) versus heritage culture preservation (separation)) as a theoretical background for interpreting results.

\section{Schumann's Acculturation Model for L2 Acquisition}

Schumann's (1978) acculturation model theory investigates SLA from a social-psychological point of view; it mainly describes the process of L2 learning in natural contexts of majority language setting by members of ethnic minorities coping with the culture in their new surrounding society. In his model Schumann (1986, cited in Zaker 2016) identified two key sets of variables that explain differences in L2 acquisition: social variables represented in the social distance that L2 learner has towards the target language group or the degree of actual contact within the TL community, and affective variables (psychological distance) represented in individual's response to the language learning experience; how comfortable the learner is towards the surrounding social factors and to what extent he/she wants to acculturate with the hosting culture.

Schumann places both social and psychological variables on similar scales lying along a continuum running from social-psychological distance to social psychological closeness with L2 speakers and posited that success in L2 learning depends primarily on the degree of reducing the social and psychological distance between the home culture and mainstream culture. Schuman (1978) assumed also that the effect of both factors on SLA is not equal; with affective factors, mainly motivation, probably having more influence than social factors.

Moreover, Schumann (1975) identified five affective variables that directly impact the psychological distance: motivation (the degree and type of desire (integrative/instrumental) experienced by the learner to acquire the L2), Ego permeability (accepting the idea of having a new identity associated with the belonging to a new speech community), language shock (to what extent does learning the TL linguistic system make the learner disoriented?), culture shock (the extent to which the learner feels confused and stressed due to interacting in a new culture) and Culture stress (Prolonged culture shock and questioning self-identity with extended residence in a new culture). A point of strength in 
Schumann's model is integration; as it focuses on the socio-cultural context of SLA without abandoning the individual role in the $\mathrm{L} 2$ acquisition process.

Based on the wide variation in linguistic and cultural experiences encountered during study abroad, previous research on SLA and acculturation within the cultural context of the target language has documented extensive variation in the amount of contact students have with members of the local community as well as in their linguistic outcomes. Gursoy's and Kunt's (2019) study addressed the acculturation process experienced by a sample of university students studying EFL in Northern Cyprus. It focused mainly on the role cultural and motivational factors play in acquiring an L2. The sample of the study included ten participants of Turkish, Azeri, Uygur (China) origin, and Palestinian students. In-depth interviews reveal that all students involved in the acculturation process display a separation strategy, with Turkish students as an exception, as they have more motivation to integrate with the host culture. The study findings assured two main points; first, the closer the students' culture to the culture of the target language and host culture, the better the acculturation process will prove to be; second, cultural background and motivation are closely interrelated in the learner acculturation process.

Ndika's (2013) study aimed at investigating the acculturation coping strategies of first-generation Nigerian immigrants in the United States. Through Discrimination Function Analysis (DFA) five coping strategies were detected: integration, assimilation, separation, assimilation and separation, and integration and assimilation. Assimilation and separation strategies were the most frequent while integration was the least reported. In his study, Waniek-Klimczak (2011) focused on studying the correlation between the chosen acculturation strategy and proficiency level in English as a second language. Sample of the study were recent Polish immigrants to the UK. Results of the study questionnaire were analyzed in terms of socio-affective factors and language proficiency. Findings revealed that proficient language users tend to adopt an assimilation strategy rather than integration. L2 learners' attitudes towards the host culture are related to their proficiency level in the target language in a more cautious way.

A study by Rose (2008) investigated the nature of the relationships between foreign language anxiety, acculturation, and acculturative stress as it is experienced by adult Spanish speaking immigrants living in the United States. Combining questionnaire results with the analysis of six semi-structured interviews, final results indicated that language acquisition in the adopted country when accompanied by the regular processes of acculturation may produce higher levels of language anxiety. The study recommends, focusing on language attitudes and beliefs, as to how those attitudes and beliefs are intertwined with acculturation and acculturative stress may produce a deeper understanding of language acculturation anxiety.

The majority of these studies (Gursoy \& Kunt,2019; Rose, 2008; Waniek- Klimczak, 2011) targeted populations whose home language belongs to Indo-European language and learn English as SL including cases from both studyabroad and at-home contexts. Since English belongs to the same language family, acquiring it can be quite different from learning a language of a different family. On the contrary, the current study investigating those who speak English (as an Indo-European language) and learn Arabic, a different language family, abroad; thus, a significant but neglected bilingual population was explored in the current study.

Within the context of ASL, previous related studies focused mainly on either investigating linguistic identity, and forms of imagined communities among ASL learners or the cultural and social factors affecting Classical Arabic language teaching and learning. A study by Al-Sobait (2019) investigated the nature of the linguistic identity, level of language investment, and forms of imagined communities among learners of Arabic as a second language. The sample of the study included 40 female ASL learners in Riyadh city, KSA. Two main instruments were used: a questionnaire and an interview. Results revealed that there was a conflict between language and the home culture as well as language and target culture concerning values, behaviour, and customs which in turn result in a kind of conflict in the learner's identity.

Alareik's (2016) study aimed to first, identify the cultural factors related to teaching foreign languages in general and Arabic language in particular and their effect on language acquisition; second, investigate the social factors affecting Classical Arabic language (Alfushaa) teaching and learning; these social factors cover the type of the language and social adaptation level, the attitude towards the target culture and reversed opinions as well as the social role in language dissemination. The sample of the study consisted of ASL learners in the Arabic Institute, King Saud University, KSA. The study used a ten-item questionnaire. Results revealed that there is a kind of social isolation that those learners live in the hosting culture that in turn slow the process of language acquisition and there is no active participation from the target community to support the social integration of those learners in the society. Pre-formed concepts or imagined pictures about the target culture affects negatively second language acquisition.

Temples (2013) tried to explore the complexity of the ASL learning process by linking L2 learning, identity construction, and biliteracy challenges and implications for Arabic learners from a range of backgrounds. The sample of the study included a group of ASL learners at a public charter middle school in the southeast U.S. the study depended on three main instruments: interviews with five focal families, class observations, and surveys. Results revealed that social context affects literacy development as well as identity construction for heritage learners. Trentman (2013) used three theoretical concepts, investment, imagined communities, and communities of practice, to explicate data obtained from Arabic as a second language (ASL) students studying abroad (in Egypt). Findings revealed that though ASL students started the study abroad experience with a desire to get involved in an imagined Middle East community 
through demonstrating the identities of cross-cultural mediators and dedicated language learners, the real communities of practice provided distinctive and dissimilar chances to demonstrate these identities. Thus, there was a clear area of alignment and misalignments between what was imagined and reality. Moreover, the large-scale dissimilarities in students' adopted strategy to approach TL speakers (Egyptians) and their use of TL can be attributed to the extent of the alliance between students' expectations and the real world they lived in.

These studies have corroborated the complexity of studying Arabic as a second language abroad and the multi-factors affecting this process at both linguistic and social levels. This study instead focused on how individuals' motivations for learning Arabic as L2 interplay with their acculturation coping strategy, rather than specific individual or program factors, to explain variation in language acquisition and engagement in the host culture.

\section{E. Motivational Orientation and Second Language Learning}

The orientation towards mastering a second language usually stems from a wide range of deeply valued motivations. Within the L2 literature, there are two interrelated concepts: motivations, "why" learners trace a particular goal, and goals, "what" goals are traced. Sheldon, Deci, and Kasser (2004) state that understanding these two concepts are "two of the most important theoretical and empirical forces of motivation” (p. 447 as cited in Rubenfeld et al., 2007 p. 311 ). Moreover, in his socio-educational model of second language acquisition, Gardner (1985, 2000) referred to these two concepts as motivations and orientations. According to Gardner, motivation refers to behavior and efforts individuals exert to pursue learning an L2 as well as, a desire to learn that language and positive attitudes toward the learning process; whereas orientation refers to a person's reasons for learning a second language.

Gardener classified motivation in SLA context into two main categories, integrative and instrumental motivation that has been considered as essential foundations of the acculturation model. Choosing between these two categories depends mainly on the learner's goal, desires, and attitudes towards the target language community; accordingly, the learner tends to be integratively motivated when s/he held positive attitudes towards the target language community and values its culture.

A considerable amount of research demonstrated connections between attitudes, motivation and SL proficiency A study by Alamaj (2019) aimed at exploring the cognitive, affective, and behavioral attitudes of ASL learners towards learning it and to what extent their linguistic level will affect their attitudes. The sample of the study consisted of 22 female students studying a general Arabic language course at Princess Nourah Bint Abdulrahman University. The findings of the study revealed that participants' behavioral attitudes were dominantly represented in their desire to communicate with female home speakers, followed by cognitive attitudes, and the affective attitudes. This study was taken into account in designing the motivational orientation for learning Arabic as an L2 scale as well as discussing the results of the present study.

A study by Alosaimy (2011) investigated ASL learners' perceptions towards themselves as second language learners, successful learning of the Arabic language, and nature of the Arabic language in terms of difficulty and easiness as well as the leaning context. The sample included 142 ASL male learners, in the institute of teaching Arabic language, Imam University, Saudi Arabia. The results revealed that participants perceive themselves as knowledge seeker, and successful learning of Arabic language depends on communication with home speakers. This study was beneficial to the present study since it focused on exploring ASL learner's perceptions, as perception is part of the cognitive component of attitudes that is essential in developing positive attitudes and modifying the negative ones.

\section{MEthodology}

\section{A. Overall Design of the Study}

Though it is a descriptive research in nature, this study is also considered to be correlational, as it investigates the correlation between second language acquisition, motives for learning Arabic as a second language and adaptation in the foreign culture (Saudi culture) as well as cultural stress experienced in the hosting society. As features related to L2 learners, including motivational orientation, and factors related to the learning environment cannot be fully addressed by the "snapshot" view that survey methods usually produce (Temples, 2013), mixed-method was utilized to get more reliable results and eliminate any possible inclination.

\section{B. Participants}

The participants of the study included a sample of 50 female bilingual English-speaking adults learning Arabic as a second language (ASL) in Saudi Arabia. They were living in Saudi Arabia as family members. They have different cultural backgrounds which do not share any linguistic, cultural similarities as well as geographic proximity with Arabic context in Saudi Arabia (see Table 1 for a summary of participants' demographic information). 
TABLE 1.

SUMMARY OF PARTICIPANTS' SOCIODEMOGRAPHIC INFORMATION

\begin{tabular}{|c|c|c|c|c|}
\hline Variable & & Category & $\mathrm{N}$ & percentage \\
\hline \multirow[t]{3}{*}{ Age } & & $20-30$ & 12 & $24 \%$ \\
\hline & & $30-39$ & 24 & $48 \%$ \\
\hline & & $40-50$ & 14 & $28 \%$ \\
\hline \multirow{15}{*}{$\begin{array}{c}\text { Nationality } \\
\text { (Cultural background) }\end{array}$} & \multirow{4}{*}{ Europe } & Italian & 4 & $8 \%$ \\
\hline & & French & 3 & $6 \%$ \\
\hline & & Ukrainian & 5 & $10 \%$ \\
\hline & & Spanish & 4 & $8 \%$ \\
\hline & \multirow{6}{*}{ America } & American & 4 & $8 \%$ \\
\hline & & Nicaraguan & 2 & $4 \%$ \\
\hline & & Guatemalan & 2 & $4 \%$ \\
\hline & & Venezuelan & 2 & $4 \%$ \\
\hline & & Argentinian & 4 & $8 \%$ \\
\hline & & Mexican & 4 & $8 \%$ \\
\hline & Asia & Indian & 5 & $10 \%$ \\
\hline & & Pakistani & 4 & $8 \%$ \\
\hline & & Turkish & 3 & $6 \%$ \\
\hline & & Malaysian & 3 & $6 \%$ \\
\hline & & Japan & 1 & $2 \%$ \\
\hline \multirow[t]{3}{*}{ Length of residence } & $1-5$ & & 36 & $72 \%$ \\
\hline & $6-10$ & & 10 & $20 \%$ \\
\hline & More than 10 & & 4 & $8 \%$ \\
\hline
\end{tabular}

All participants were enrolled in a non-intensive ASL program in the Arabic Language Teaching Institute, Imam Mohammed Ibn Saud Islamic University, Riyadh. After consulting the teaching staff and program coordinator, it was determined that only students at higher levels ( 3 and above) would be capable of completing the study scales.

Participants' level of Arabic language proficiency (based on pen and paper placement tests) was accepted 'preintermediate' in the program at the time of the study. Yet, the present study focused on using participants' selfperceived proficiency level, based on their capability of interacting successfully in daily life situations in the Saudi community. The rational for this is to explore the actual level of their oral language proficiency level based on their authentic interaction experiences with native speakers. Results revealed that there is a great range in scores with the majority (40\% - 20\%) reporting beginner and post-beginner levels; $14 \%$ reported pre-intermediate level, and only $8 \%$ reported that they are at upper intermediate level.

\section{The Study Context}

This study was conducted in one main state in Saudi Arabia, namely Riyadh, where approximately 300 multicultural students from more than 11 different countries join programs for studying Arabic as a foreign language at governmental universities. The main mission of Arabic Language Teaching Institute, Imam Mohammed Ibn Saud Islamic University, where this study was conducted, is targeting non-Arabic speakers in Riyadh from all nationalities to enable them to produce oral and written language that is accurate, fluent and high in quality. For admission, the student must have a high school certificate or equivalent; students should take admission and placement tests administered by the Institute. The institute presents intensive and non- intensive programs. The non-intensive program that the study participants join includes eight levels delivered over three years. Each level lasts for three hours per day, two days a week, for 8 weeks (72 hours). Standard Arabic is the variety of Arabic taught in the institute.

\section{Data Collection Instruments}

\section{Motivational Orientation for Learning Arabic as a Second Language Scale}

The questionnaire includes two sub-scales of motivational orientations (integrative and instrumental). The development of the questionnaire was based on the research questions and review of existing literature previously conducted in this field. The questionnaire items were adapted from instruments from previous studies (The Motivation and Attitude Questionnaire developed by Dörnyei (1990); the Language Learning Orientations Scale (LLOS; Noels et al., 2000); Midraj et al., (2015); Öztürk \& Gürbüz , 2013) that had been conducted in fields similar to this study.

The questionnaire in its final form consisted of two main Sections. Section one: (4 items) dealt with sociodemographical data such as age, nationality, length of residence in Saudi Arabia, and one item about respondents' selfrating of Arabic language proficiency level. Section two: included 37 statements on a 5-point Likert-type attitudinal scale about motivational orientation (integrative 21 items \& instrumental 16 items) towards learning Arabic as a second language.

2. Acculturation scale

The acculturation scale was used to measure participants' acculturation progress in two dimensions: Separation /adjustment to the ethnic society (AES) and Integration/adjustment to dominant society (ADS), respectively. The scale was adapted from The Stephenson Multigroup Acculturation Scale (SMAS; Stephenson 2000) as well as questionnaires used by other related studies such as Gursoy \& Kunt, 2019; Mei, et al.,2009; Ndika, 2013; Rubenfeld, et al., 2007. The scale included 32 items on a four-point Likert scale from 1 (false) to 4 (true). Fifteen items measure participants' 
integration in the hosting Saudi society and seventeen items assess participants' adjustment to their home society. The scale items represent a wide range of attitudes and behaviors related to language and social interaction.

\section{Scale of Language Acculturative Stress}

The scale consisted of 35 statements, measured on a five-point Likert scale from 1 (nothing of stress) to 5 (Very much stress). Each phrase presents social interaction situation; participants have to read each phrase and decide if they experienced the situation in the last four months, circle 'YES'; then circle the number that best represents the degree of stress they felt in that situation. The scale items were formed in light of the research aim, questions, and reviewing questionnaires used in other related studies e.g. the Multidimensional Acculturative Stress Inventory by Rodriguez, Myers, Mira, Flores, and Garcia-Hernandez (2002).

Validation of research instruments

To validate the three scales, they were submitted to 5 specialized jury members. They were asked to provide their opinions in terms of the extent to which the scales were suitable for application and deciding whether some items needed to be modified, added, or omitted. Their suggestions such as rewording some items for clarity and defining a few terminologies were used to improve the scales. As for reliability, the Cronbach's alpha index (Cronbach, 1951) was calculated to determine the internal consistency of the different items in each scale; that is, how closely related the set of items were in the scale. The reliability coefficients showed that the three scales had acceptable internal consistency within each section (at.85 and .83 for the Motivation scale; 0.87 for the entire acculturation scale, 0.95 for the integration items and 0.92 for separation items; and 0.89 for the acculturative stress scale). To prevent misunderstanding and increase the reliability of the study, participants received both English and back-translated Arabic versions of the three scales.

4. Semi-structured interview

To elicit information and obtain in-depth data about participants' motivational orientation, beliefs, cultural experiences, and underling factors affecting their language acculturation process, a follow-up semi-structured interview with eleven participants (who agreed to participate) was used. The participants were selected from the main research sample using the stratified random technique to ensure having a well-rounded sample. Participants had to answer five open-questions focusing on reasons for learning Arabic language, language learning experience, and difficulties encountered; acculturation problems they experienced, and their selected coping strategy. Participants had the choice to be interviewed in English or Arabic. Participants set for the interview after receiving a detailed description of the interview aim, procedures and content, as well as ethics rules.

\section{RESULTS}

\section{A. Quantitative Results}

Quantitative data analysis through descriptive statistics of frequency and central tendency was used to analyze the data of the study scales and answer the research questions, as follows:

1. Participants' Motivational Orientation towards Learning ASL

To answer the research first question, descriptive statistics were used to calculate the percentage and mean score for the general motivation level and each type (integrative $\&$ instrumental). See table (2)

TABLE 2.

PARTICIPANTS’ MOTIVATIONAL ORIENTATION LEVEL AND TYPE

\begin{tabular}{|c|c|c|c|c|c|}
\hline Motivational type & Level of motivation & Frequencies & Percentages & Mean & SD \\
\hline \multirow{3}{*}{ Integrative } & Low & 4 & 0.08 & 68.7500 & 6.75154 \\
\hline & Moderate & 32 & 0.64 & 99.7813 & 6.49434 \\
\hline & High & 14 & 0.28 & 117.6429 & 5.24195 \\
\hline \multirow{5}{*}{ Instrumental } & Total & 50 & 100 & 102.30 & 14.144 \\
\hline & Low & 18 & 0.36 & 39.6111 & 9.72044 \\
\hline & Moderate & 23 & 0.46 & 55.4348 & 3.94077 \\
\hline & High & 9 & 0.18 & 70.2222 & 2.99073 \\
\hline & Total & 50 & 100 & 52.40 & 12.805 \\
\hline \multirow{4}{*}{ General level } & Low & 4 & 0.08 & 102.2000 & 21.27675 \\
\hline & Moderate & 36 & 0.72 & 153.3714 & 10.01788 \\
\hline & High & 10 & 0.20 & 185.6000 & 8.73308 \\
\hline & Total & 50 & 100 & 154.70 & 24.453 \\
\hline
\end{tabular}

Table (3) shows that participants' motivational orientation level towards learning the Arabic language was generally moderate $\left(0.72 \%, m_{-} 153.3714\right)$. As for type of motivational orientation, participants' instrumental scores had a significant lower mean (m_52.40) than integrative scores (m_102.30). Furthermore, for detailed analysis of participants' integrative and instrumental motivations, frequencies and percentages related to low, moderate and high were calculated. Results revealed that $14(0.28 \%)$ of participants demonstrated a high level of integrative orientation, and $32(0.64 \%)$ had a moderate level. On the other hand, only $9(0.18 \%)$ participants reported a high level of instrumental orientation, and $36(72 \%)$ reported a moderate level of instrumental orientation. Results revealed also that there was a significant relationship between the two types of motivation (integrative and instrumental), $\mathrm{t}(0.646)$. 


\section{Participants' Language Acculturation Level and Strategy in the Saudi Society}

To answer the research second question, descriptive statistics were used to calculate first, the mean score for each item of the acculturation scale, then percentage, mean and SD for general acculturation level and each coping strategy. See table (3).

TABLE 3.

PARTICIPANTS' ACCULTURATION LEVEL AND TYPE

\begin{tabular}{|c|c|c|c|c|c|}
\hline Motivational type & Level of motivation & Frequencies & Percentages & Mean & SD \\
\hline \multirow{3}{*}{ integration } & Low & 8 & 0.16 & 24.50 & 4.472 \\
\cline { 2 - 6 } & Moderate & 33 & 0.66 & 36.73 & 5.101 \\
\cline { 2 - 6 } & High & 9 & 0.18 & 51.44 & 4.187 \\
\hline \multirow{3}{*}{ separation } & Total & 50 & 100 & 37.42 & 9.296 \\
& Low & 3 & 0.06 & 25.00 & 6.928 \\
\cline { 2 - 6 } & Moderate & 14 & 0.28 & 46.93 & 5.757 \\
\cline { 2 - 6 } & High & 33 & 0.66 & 60.30 & 4.172 \\
\cline { 2 - 6 } & Total & 50 & 0.80 & 54.44 & 10.698 \\
\hline \multirow{3}{*}{ General level } & Low & 4 & 0.48 & 83.75 & 14.592 \\
\cline { 2 - 6 } & Moderate & 24 & 0.44 & 105.00 & 6.400 \\
\cline { 2 - 6 } & High & 22 & 100 & 91.86 & 16.015 \\
\cline { 2 - 6 } & Total & 50 & & & 16.383 \\
\hline
\end{tabular}

Table 4 shows that participants reported a moderate level of acculturation (m_91.86). On the acculturation scale subtests (integration \& Separation), results revealed that participants' mean score was $37.42(\mathrm{SD}=9.296)$ concerning adjustment to the hosting Saudi culture (Integration), and 54.44 (SD 10.698) concerning adjustment to home culture (Separation).

3. Participants' Perceived Acculturative Stress Level

To answer the research third question, descriptive statistics was used. See table (4).

TABLE 4.

Participants' PerCeived LeVEl OF ACCUltuRATIVE STRESS

\begin{tabular}{|c|c|c|c|c|}
\hline acculturation stress level & Frequencies & Percentages & Mean & SD \\
\hline Nothing of stress & 6 & 0.12 & 35.00 & 0.000 \\
\hline A little of stress (low) & 35 & 0.70 & 49.37 & 9.082 \\
\hline Some stress (medium) & 7 & 0.14 & 82.00 & 10.182 \\
\hline A lot of stress & 2 & 0.04 & 123.50 & 7.778 \\
\hline Very much stress & 0 & 0.00 & 0 & 0 \\
\hline Total & 50 & $100 \%$ & 55.18 & 20.938 \\
\hline
\end{tabular}

As shown in table 5, all participants reported that they do not experience very much stress in the Saudi cultural context; with the majority of the participants reported a little of acculturative stress $\left(0.70 \% \_\mathrm{m}=49.37\right)$.

In light of preliminary analyses, demographic information about nationality, age, length of residence in an Arabicspeaking country and self-perceived level (self-rating) of Arabic language ability were used as covariates in all analyses after adjusting degrees of freedom (DF) and estimating values of partial correlation. The correlations between the study variables revealed that the variables with the strongest correlations with language proficiency level were length of residence, and age (b-.342; -.458). The second strongest correlations with language proficiency level were motivation level, nationality, acculturation level, and acculturative stress (b -0.27, -.053-. -.079-,.093- t (46)-1.97, p.0.05. The variable with the strongest inverse correlation with acculturation level was perceived acculturative stress (-.280-), general motivation level and integrative motivation $(-.271-,-366)$.

4. Multiple regression analysis

Trying to answer the research fourth, after testing the correlation among variables, multiple regression analysis step was done using language acculturation as the dependent variable and all the other variables as independent variables. To examine to what extent the independent variables shared variance and to declare what set of factors best predict language acculturation level in the hosting society. See table 5. 
TABLE 5.

CORRELATION AND COEFFICIENT RESULTS OF THE CORRELATION BETWEEN ACCULTURATION AND OTHER STUDY VARIABLES

\begin{tabular}{|c|c|c|c|c|c|c|c|c|c|}
\hline \multirow[b]{2}{*}{ Model } & \multicolumn{3}{|c|}{ Unstandardized Coefficients } & $\begin{array}{l}\text { Standardized } \\
\text { Coefficients }\end{array}$ & \multirow[b]{2}{*}{$\mathrm{t}$} & \multirow[b]{2}{*}{ Sig. } & \multicolumn{3}{|c|}{ Correlations } \\
\hline & & & Std. Error & Beta & & & Zero-order & Partial & Part \\
\hline \multicolumn{2}{|c|}{ (Constant) } & 102.612 & 24.522 & & 4.184 & .000 & & & \\
\hline \multicolumn{2}{|c|}{ Length of residence } & $-.388-$ & .868 & $-.086-$ & $-.447-$ & .657 & $-.164-$ & $-.069-$ & $-.062-$ \\
\hline \multicolumn{2}{|c|}{ Age } & .090 & .356 & .042 & .02 & .800 & $-.115-$ & .039 & .036 \\
\hline \multicolumn{2}{|c|}{ Nationality } & $-.387-$ & .798 & $-.087-$ & $-.041-$ & .657 & $-.162-$ & $-.065-$ & $-.061-$ \\
\hline \multicolumn{2}{|c|}{ Language Level } & $-2.583-$ & 2.418 & $-.217-$ & $-1.068-$ & .292 & $-.207-$ & $-.163-$ & $-.149-$ \\
\hline \multicolumn{2}{|c|}{ Integrative } & .290 & .272 & .250 & 1.065 & .293 & .073 & .162 & .149 \\
\hline \multicolumn{2}{|c|}{ Instrumental } & $-.315-$ & .271 & $-.246-$ & $-1.161-$ & .252 & $-.012-$ & $-.176-$ & $-.162-$ \\
\hline \multicolumn{2}{|c|}{ Stress } & $-.241-$ & .124 & $-.308-$ & $-1.950-$ & .058 & $-.280-$ & $-.288-$ & $-.272-$ \\
\hline
\end{tabular}

Table 6 shows that while $t$ values of some independent variables (length of residence, language level, motivation and acculturative stress) are above $0.05[\mathrm{~F}(1.313)=0.268 \mathrm{~b}, \mathrm{p}>0.05]$, variables of age and nationality got 0.04 and 0.2 ; thus, it can be said that only age and nationality had a statistically significant effect on the explanation of variance in the dependent variable (acculturation).

\section{B. Qualitative Results (Results of the Interview)}

The three main themes emerged from the interview were as follows:

\section{Motivational orientation towards learning ASL}

Asked about their reasons behind studying the Arabic language most of the participants (55\%_ more than half) reported that their main aim is to be able to communicate in Arabic and understand Saudi people as well as introduce themselves to this culture; one of the participants stated that "I live in Saudi Arabia, so it's useful and important to know the local language"; another participants said "I want to communicate with Arab people in a much easier way and have a better social life". The second reason (36\%) was to learn the language of the Quran. One of the participants reported "I want to learn Arabic to read the Quran in the original language. The third reason was being interested in learning a new language $(27 \%)$. The least reported reason $(18 \%)$ was for further education and a better job; stated by only two participants. This suggests a great deal of consensus among the participants regarding the integrative value of learning Arabic. This section of the interview indicates parallelism with the quantitative data of the study.

\section{Language Learning Experience}

The second question of the interview focused on participants' experience as language learners (speaking anxiety, feeling their identity). Asked about situations that make them feel uncomfortable in speaking Arabic, more than half of the participants reported they feel uncomfortable when they communicate with Arabic speakers who use the local dialect 'Amaya' not Standard Arabic 'Fusha' that they study in the institute. One participant stated, "I cannot let them understand me; when I don't find the exact word that I need”. Asked about the identity they feel when speaking Arabic, more than half of the participants reported that they feel different personalities when speaking Arabic; one participant reported: "I have an alter-ego when I'm speaking Arabic". Others reported that they feel their ethnic identities. As for their recommendations for SL teachers, participants agreed on the benefits of receiving immediate feedback with some sort of visual reinforcement, teacher's friendly personality and attitude, speaking only Arabic in class, and differentiated instruction depending on students' learning speed, not the content. They also stressed on integrating colloquial Arabic in class communication to help them communicate effectively in daily life situations.

\section{Social Context and L2 Acquisition}

Asked about their language acculturation experience in Saudi society and in what ways the daily communication is similar or different to their home societies, participants' responses (87\%) suggest fairly positive feelings towards interacting within Saudi society. One of the participants stated that "although Saudi Arabia is often a misjudged country in the western world when I had the chance to experience on my own its culture, traditions and people, I started to love and appreciate it, in some ways even more than western countries.". They stated some reasons for these positive feelings: Saudi people being very friendly and generous, social life with religious atmosphere and behaviours including homosexual acts, and the way women are treated with the respect of their modesty and rights;

Asked about challenges they face in their acculturation process in Saudi society as 12 as non-native speakers of Arabic and how they cope with them. Most participants (88\%) reported that language barriers and cultural differences are the two main causes of acculturative stress; some participants (42\%) responded that they used to have difficulties communicating with people, but now at pre- intermediate Arabic language level they could communicate with others and understand people speaking in Arabic, and that this had helped them cope with many problems. One participant said "I was always too shy to negotiating with store/shop workers. Now, in certain places, I have improved my ability to be more assertive to avoid being overcharged. After I learned how to communicate in Arabic, I feel like people take me more seriously." As for the acculturation coping strategies, most participants (83\%) reported that they try to understand the Saudi traditions to speak and behave appropriately in social situations whereas they maintain their home culture. 


\section{DISCUSSION}

An important aspect of the present study is the use of instruments (three scales) that are based on adapting relevant questionnaires with the study population in mind instead of just a mere translation of instruments adopted from previous research that might result in culturally inappropriate or irrelevant instruments. Based on the quantitative data, the study results revealed that participants are quite eager to learn Arabic as a foreign language with the majority reporting a moderate level of integrative motivation. According to the qualitative data of the interview, most respondents, aiming to achieve what Kramsch (2006) refers to as 'self-fulfilment', reported their desire to introduce themselves to Arabic culture.

Results revealed also that general motivation as well as integrative motivation levels had the second strongest positive correlation with language self-rating proficiency level. This result is inconsistent with Gardner and lambert's theories, which stressed that integrative motivated L2 learners surpass those who are instrumentally motivated in terms of language proficiency level, as well as the findings of previous related studies (Dornyei, 2005; Midraj's et al., 2003) which proved a significant positive correlations between SL achievement level and willingness to spend time on learning it (integrative motivation).

According to the results of the interview, while most of the participants $(55 \%)$ reported that their main motive for learning Arabic is to learn colloquial Arabic varieties and use newly acquired vocabulary in street/informal authentic situations, some participants (36\%) reported that they aim to learn Standard Arabic to read the Holly Quran correctly. This discrepancy reflects one of the major challenges that face ASL teachers/learners, the dual use of Arabic language (diglossia). Therefore, it is essential for ASL courses designers and teachers to find ways to increase learners' exposure to the two varieties of the language in a balanced way to meet their real needs.

Quantitative results of the language acculturation scale indicated that participants were without exception still more adjusted to their home culture than to the Saudi culture. This result is consistent with the results of Alareik's study (2016), which revealed that there is a kind of social isolation that ASL learners live in the Arabic community that in turn slow the process of language acquisition. Yet, finding contrasts with the qualitative data of the interview.

This contradiction is explained by Kim (2009) who declared that during the process of acculturation, people with multicultural backgrounds might tend to develop what is called 'identity flexibility' that might help them to accommodate more readily and respect the differences between their home culture and the hosting culture. Also, Bilingualism can be considered as a variable in enhancing participants' expertise in language acculturation in the Arabic society; especially that their bilingualism was between very different language families, cultures (e.g. Turkish - English, Japanese-English). One more possible interpretation is gender (all females). Females have a sociable character and tend to build relationships with others. Also, most of the participants are housewives; thus, acculturation to the host country's language (Arabic) may be seen as a solution to the many practical problems of living abroad for a long time. According to Van Deusen-Scholl (2003) Arabic is a commanding language, important for cultural and interpersonal aims among families and individuals live in the Arabic speaking community and for whom it is a binding force.

Multiple regression analysis proved that only participants' cultural background (nationality) and age had a statistically significant effect on the explanation of variance in language acculturation process. Mainly European got the highest correlation followed by home Americans and Japanese. This can be referred to what Schumann called 'social distance' between participants' home cultures and the hosting culture. The more similar the two cultures, the more likely there will be social contact and thus language acquisition.

The insignificant correlation between other socio-demographical data and acculturation was not unexpected. This can be returned to the wide variation in participants' age. Previous research proved that differences in age are clearer only when comparing younger populations (MacIntyre, Clement, Baker \& Conrod, 2002) rather than considering a heterogeneous population. We were, however, surprised that the length of residence was not linked to the language acculturation process, as previous research has shown that integrative acculturation is linked to longer residence periods (Dewaele, 2010). But again this can be attributed to the complexity of the Arabic language

\section{CONCLUSION}

Overall, this study added to the study of L2 learning abroad, motivational orientation, and language acculturation in a novel context like Saudi context with a multicultural background sample. It sought to highlight the sociopsychological factors of SL learners in multicultural environment; thus, provide effective implications concerning the importance of developing L2 learners and teachers' intercultural competence and cultural diversity. Although rich data have been cumulated in this study, further research can be conducted with larger sample using different predictors, such as gender, type of socioeconomic status, identity type, academic and cultural backgrounds, religion. Also, investigating the degree of cohesiveness to the hosting society by L2 learners and how this affects their pragmatic competence, needs more research. Finally, the qualitative data of the interviews with a small sample size my presents only a 'flash light' reference of the underlying factors affecting L2 acculturation process in the hosting society. Future studies are suggested to increase the sample size of the interviews or include other measures (e.g., think-aloud and reflective journals) for getting more in-depth data. 


\section{REFERENCES}

[1] Alamaj Nouf. (2019). The Attitudes of Female Learners of Arabic as a Second Language Towards Learning It. MA thesis, Institute of Arabic Language Teaching, Imam Mohammed Ibn Saud Islamic University.

[2] Alareik, Abdelhamid. (2016). Some Social Factors Affecting Second Language Teaching. Culture and Development, 109(17) 165-189. Retrieved 05/20/2019, from https://search.mandumah.com/Record/802222.

[3] Al-Batal, M. (2007). Arabic and national language educational policy. Modern Language Journal, 91(2), 268-271.

[4] Allen, R. (2007). Arabic - "flavor of the moment": Whence, why, and how? Modern Language Journal, 91(2), $258-261$. https://doi.org/10.1111/j.1540-4781.2007.00543_6.x.

[5] Alosaimy Fhad. (2011). Arabic Language Learners and Their Religious Needs. The $7^{\text {th }}$ international conference of Arabic Language, Role of Arabic Language in Civilization Building Process, Indonesia: Etehad Moalmy Alfekr, Jakarta

[6] Al-Sobait Walaa. (2019). Identity, language investment and imagined communities among learners of Arabic as a second language. Unpublished PhD dissertation, Al-Imam Muhammad IbnSaud Islamic University- Institute of Arabic Language Teaching, Saudi Arabia.

[7] Berry, J. W. (1997). Immigration, acculturation, and adaptation. Applied psychology: An international review, $46(1), 5-34$.

[8] Berry, J. W. (2003). Conceptual approaches to understanding acculturation. In K. M. Chun, P. B. Organista, \& G. Marı'n (Eds.), Acculturation: Advances in theory, measurement, and applied research (pp. 17-38). Washington, DC: American Psychological Association.

[9] Bluestone Kathy. (2015). Acculturation, Interpersonal Networks, and the Learner's Sense of Self: The Effects of Social Relationships on Second Language Learning. TESOL Web Journal. DOI: 10.7916/D8TB1KGM.

[10] Dewaele, J.-M. (2010). Multilingualism and affordances: Variation in self-perceived communicative competence and communicative anxiety in French L1, L2, L3 and L4. International Review of Applied Linguistics, 48, 105-129.

[11] Dewaele Jean-Marc and Al-Saraj Taghreed. (2015). Foreign Language Classroom Anxiety of Arab learners of English: The effect of personality, linguistic and sociobiographical variables. Studies in Second Language Learning and Teaching, 5 (2). 2015. 205-228. doi:10.14746/ssllt.2015.5.2.2.

[12] Dörnyei, Z. (2003). Attitudes, orientations, and motivations in language learning: Advances in theory, research, and applications. Language Learning, 53, 3-32.

[13] Dornyei, Z. (2005). Motivation and self-motivation. The psychology of the language Learner: Individual differences in Second Language Acquisition. Mahwah, New Jersey: L. Erlbaum. 65-118.

[14] Gardner, R. C. (1985). Social psychology and second language learning: The role of attitude and motivation. London: Edward Arnold.

[15] Gardner, R.C. (2000). Correlation, causation, motivation and second language acquisition. Canadian Psychology, 41, 1-24.

[16] Gardner, R. C. (2001). Integrative motivation and second language acquisition. In Z. Dörnyei \& R. Schmidt. (Eds.), Motivation and second language acquisition (pp.1-16). Honolulu, HI: University of Hawaii at Manoa.

[17] Gardner, R. C. (2006). The socio-educational model of second language acquisition: A research paradigm. Eurosla Yearbook, 6 (1), 237-260.

[18] Graham C. Ray \& Brown Chery. (1996). The Effects of Acculturation on Second Language Proficiency in A Community with A Two-Way Bilingual Program. The Bilingual Research Journal Spring, 20, (2), 235-260

[19] Gursoy Salih \& Kunt Naciye. (2019). Acculturation of university students in Northern Cyprus, Culture \& Psychology, 2019, 25(2) 146-160, DOI: 10.1177/1354067X18808213.

[20] Hall Joan, Cheng An \& Carlson Matthew. (2006). Reconceptualizing Multicompetence as a Theory of Language Knowledge. Applied Linguistics, Volume 27, Issue 2, June 2006, 220-240, https://doi.org/10.1093/applin/aml013.

[21] Jackson, F. H., \& Malone, M. (2009). Building the foreign language capacity, we need: Toward a comprehensive strategy for a national language framework. Washington, DC Centre for Applied Linguistics.

[22] Kim, Tae-Young. (2009). The sociocultural interface between ideal self and ought-to self: A case study of two Korean students' ESL motivation. In Z. Dörnyei \& E. Ushioda (Eds.), Motivation, language Identity and the L2 self (pp. 274-294). Bristol, England: Multilingual Matters.

[23] Kramsch Claire (2006). The Multilingual Subject. International Journal of Applied Linguistics 16 (1):97 - 110. DOI: http://doi.org/10.1111/j.1473-4192.2006.00109.x.

[24] MacIntyre, P D., Clement, R., Baker, S. C., \& Conrod, S. (2002). Willingness to communicate, social support and language learning orientation of immersion students. Studies in Second Language Acquisition, 23, 369-388.

[25] Madkour, A.A. and Haridi, E.A. (2006). Teaching Arabic to non-natives: theory and practice. Egypt: Dar El Fikr Al Arabi.

[26] Mei Jiang, Raymond J. Green, Tracy B. Henley \& William G. Masten. (2009). Acculturation in relation to the acquisition of a second language. Journal of Multilingual and Multicultural Development, 30:6, 481-492, DOI: https://doi.org/10.1080/01434630903147898.

[27] Midraj Sadiq, Midraj Jessica, O’Neill Gary and Sellami Abdellatif. (2015). The Affective Factors and English Language Attainment of Arab EFL Learners IJAES, 44 (1), 43-52

[28] Mohamed,M. Fatooh \& Othman Amina. (2015). Linguistic needs and psychological variables of Arabic as a second Language learners in Europe. A research paper presented in the international conference "Issues in Arabic language teaching for nonArabic speakers", at King Abdullah Ibn Abdulaziz International Centre for the Arabic Language, Riyada. 249-278. Retrieved 07/15/2019, from https://search.mandumah.com/Record/916339.

[29] Ndika Nnenna. (2013). Acculturation: A Pilot Study on Nigeriansin America and Their Coping Strategies. SAGE Open, October-December 2013: 1-8 DOI: 10.1177/2158244013515687.

[30] Noels, K. A., Pelletier, L. G., Clément, R., \& Vallerand, R. J. (2000). Why are you learning a second language? Motivational orientations and self-determination. Language Learning 50 (1), February 2000, pp. 57-85. DOI: 10.1111/0023-8333.00111. 
[31] Nosratinia Mania, Abbasi Mojgan \& Zaker Alireza. (2015). Promoting Second Language Learners' Vocabulary Learning Strategies: Can Autonomy and Critical Thinking Make a Contribution? International Journal of Applied Linguistics \& English Literature. 4(3). doi:10.7575/aiac.ijalel.v.4n.3p.21.

[32] Olivares-Cuhat, Gabriela. (2010). Relative Importance of Learning Variables on L2 Performance. Linguistik Online, 43 (3). DOI: https://doi.org/10.13092/lo.43.415

[33] Ozer, S., \& Schwartz, S. (2016). Measuring globalization-based acculturation in Ladakh: Investigating possible advantages of a tridimensional acculturation scale. International Journal of Intercultural Relations, $\quad 53, \quad 1-15 . \quad$ DOI: 10.1016/j.ijintrel.2016.05.002.

[34] Öztürk, G \& Gürbüz, N. (2013). Motivational Orientations of Turkish EFL Students: The Case at a State University. Journal of Language and Literature Education, 8, 62-77.

[35] Rodriguez, N., Myers, H. F., Mira, C. B., Flores, T., \& Garcia-Hernandez, L. (2002). Development of the Multidimensional Acculturative Stress Inventory for adults of Mexican origin. Psychological Assessment, 14(4), $451-461$. https://doi.org/10.1037/1040-3590.14.4.451.

[36] Rubenfeld, S., Sinclair, L., \& Clément, R. (2007). Second language learning and acculturation: The role of motivation and goal content congruence. Canadian Journal of Applied Linguistics, 10 (3), 309-323. Retrieved 09/10/2019, from https://journals.lib.unb.ca/index.php/CJAL/article/view/19748.

[37] Rudmin FW. (2009). Debate in science: The case of acculturation. Retrieved 11/27/2019, from http://www.anthroglobe.info/docs/rudminf_acculturation_061204.pdf.

[38] Schumann John. (1986). An Acculturation Model for Second Language Acquisition. Journal of Multilingual and Multicultural Development, vol.7, no. 5, January 1986. 379- 392.10.1080/01434632.1986.9994254.

[39] Schumann, J. H. (1978). The relationship of pidginization, creolization, and Decreolization to second language acquisition. Language learning, 28, 367-379.

[40] Sheldon Kennon, Deci Edward \& Kasser Tim. (2004). The Independent Effects of Goal Contents and Motives on Well-Being: It's Both What You Pursue and Why You Pursue It. Personality and Social Psychology Bulletin, Vol. 30 No. 4, April 2004 475- 486 DOI:10.1177/0146167203261883.

[41] Temples, A. (2013). Constructing Arabic as heritage: investment in language literacy and identity among young U.S. learners. Dissertation, Georgia State University. Retrieved 04/17/2019, fromhttps://scholarworks.gsu.edu/alesl_diss/25.

[42] Trentman, E. (2013). Imagined Communities and Language Learning during Study Abroad: Arabic Learners in Egypt. Foreign Language Annals, 46 (4), pp.545-564. DOI: 10.1111/flan.12054.

[43] Van Deusen-Scholl, N. (2003). Toward a definition of heritage language: Socio-political and pedagogical considerations. Journal of Language, Identity \& Education, 2(3), 211-230.

[44] Waniek-Klimczak Ewa. (2011). Acculturation Strategy and Language Experience In Expert ESL Speakers: An Exploratory Study, Studies in second language learning and teaching, 1(2), 227-145, DOI: https://doi.org/10.14746/ssllt.2011.1.2.4.

[45] Wilmsen, D., (2006). "What Is Communicative Arabic?" Handbook for Arabic language teaching professionals in the 21st century, USA: Lawrence Erlbaum Associates, 125-138

[46] Zaker, A. (2016). The acculturation model of second language acquisition: Inspecting weaknesses and strengths. Indonesian EFL Journal, 2(2), 80-87.

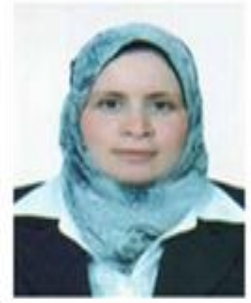

Safaa M. Abdelhalim Professor of applied linguistics/ TESOL, Faculty of Education, Helwan University, Cairo, Egypt (February, 2000 - present). Currently, she is working in College of Languages and Translation, Imam Mohammed Bin Saud Islamic University. She is an author of 14 research articles and three books in the field of applied linguistics and TESOL. Her research interests focus on teaching English as a foreign language, reflective teaching, autonomous learning strategies, second language acquisition and assessment, intercultural and cross-cultural communication, intelligent computer-assisted language learning, and second language writing.

Hajar A. Alqubayshi, lecturer (Teaching Arabic as a second language to speakers of other languages/ TASOL) at Arabic Teaching Institute, Al-Imam Muhammad Bin Saud Islamic University (2015- present). She holds a master's degree in Applied Linguistics from Al-Imam Muhammad Bin Saud Islamic University, Riyadh, Saudi Arabia (November 2019). Her master's thesis is in Computational Linguistics specifically, and its title is "Building an Algorithm for Arabic Morphological Disambiguation of the Plural of Paucity". 